\title{
Approach for Futuristic Health Care Planners
}

\author{
Gunjan Pahuja \\ JSS Academy of Technical Education, \\ Noida, India
}

\begin{abstract}
In this paper, we present a collaborative approach for the health care systems. The expert knowledge is embedded within DSS to provide intelligent decision support. The problem space contains multiple Hub and Spoke networks. Information about these networks is dynamically captured and represented in a Meta-data table. This master table enables collaboration between any two networks in the problem space, thus, enables load sharing among them. In order to show the collaboration between health care systems; number of doctors in the dispensary, present load/day and capacity are the key data to be collected for west, south, south west and south districts of Delhi before we apply this approach. The implementation is done at primary care level. The input to the model is health care data and output is a decision based on the collaborative approach model. Primary health care centers in a geographical area are transformed into Hub \& Spoke type networks. Collaboration between such networks means transfer of patient load from one network to another at primary care level depending upon free capacity available in the given network which can be determined from Meta-data table.
\end{abstract}

\section{Keywords}

Decision Support Systems, Collaborative DSS, HUB and SPOKE Model, Meta Data, Primary health care data.

\section{INTRODUCTION}

In this paper, Hub \& Spoke model and metadata information concept is used to facilitate decentralization and load balancing facilitated by collaboration. One of the key observations about healthcare services is that their demand is very uncertain. As a result, there is a regular mismatch between number of doctors' available in a hospital and number of patients or patients load per day. Thus in primary healthcare centres, people have to wait for a long time for appointments and may have difficulty in accommodating patients who have potentially urgent problems. Due to low availability and poor access of healthcare, patients suffer long delays and in particular these delays are highly undesirable, not only from a psychological point of view (patient satisfaction) but also from an economic health point of view for the health centre. Thus the need is to find the collaboration between healthcare centers in different regions. Collaboration between any 2 healthcare centres is implemented through transfer of patient load. Its advantages include providing more flexibility to system design and implementation, simplifying the decision-making process, and empowering decision makers at the operational level. Decision support system (DSS) is the system for supporting decision-maker to solve semi-structured and non-structured problems using data and model [18]. In this paper DSS algorithm is used for demonstrating the collaboration between different health care centres.
The concept of Meta-data is used to represent information about Hub and Spoke networks, in a Meta data table. This Meta-data table is searched to facilitate collaboration between two different networks. Thus the main objective of this research work is to show how the collaboration can be implemented between health care centres in a region. The approach was earlier applied on the dummy data $[2012,30]$ to validate the logic and in this paper; real time data set is used from primary health care centres in Delhi. The remainder of this paper is organized as follows:

In Section II state of art of role \& researches in health care systems using Decision Support Systems is described. Section III is the core part of the paper where we will come up with a novel way to develop Collaborative Decision Support Systems Model for Health Care Systems. Finally we will apply the technique from Section III to experimental data and present the results in Section IV .Section V provides the discussion on the results obtained in Section IV. Section VI will conclude the paper and present topics for future research.

\section{STATE OF ART}

Computerized Decision Support Systems are defined as the consultation systems that use artificial intelligence technologies for encoding the knowledge and solving the problems with that knowledge. This knowledge is represented as production rules and facts. [1986,1]. DSS has found applications in various areas like education, health care, business, agriculture production, forest management etc. Thus various frameworks or topologies have been proposed for organizing our knowledge about decision support systems. Five generic categories based on the dominant technology component are proposed, including Communications-Driven, Data-Driven, Document-Driven, Knowledge-Driven, and Model-Driven Decision Support Systems [2001, 6]. Out of these models, Model- Driven DSS emphasizes access to and manipulation of a statistical, optimization or a simulation model [2007, 14]. Clinical DSS are used for medical diagnosis. Health care sector in all countries of the world especially in third world countries is under economic crisis mainly because of its inability to achieve social justice and economic efficiency actions relating to health care services. The cost of hospital services are a function of the disease pattern of each hospital and their corresponding bed capacity $[2001,8]$. A DSS can lead to an improvement in the quality of health care services, by reducing the variations between different practices and different service providers [2005, 11]. HUB \& SPOKE model is helpful in facilitating decentralization, dynamic load balancing and planning deployment of manpower and medical. For the delivery of best information to the decision maker, integration of distributed, heterogeneous data sources, applications, and processes are required in large enterprise. Therefore new approach to solving the critical healthcare systems integration problem is proposed with the help of Metadata and Metamodel [23]. 
For comparative analysis of different hospitals and different service providers CASE MIX is used. It enables classification of patients based on disease profiles. These factors help in hospital budgeting [24]. PRODIGY (prescribed rationally with decision support in general practice) is a rule based expert system that has been developed in UK (Eddy \& Purves, 1998). This system provides advice on choice of medication and clinical recommendation for 200 clinical conditions common to general practices.

Rule based DSS also can be used for making the decisions and decisions are made by applying a set of rules, which apply on the knowledge base to return the answers to the queries asked by nursing staff, usually advice, during telephonic consultation, provided by a call centre [2001,7] . A rule based DSS, can be used especially in off-hours for patient counseling. DSS can help in monitoring disease patterns and implement patient segregation, thereby contributing to more effective monitoring and budgeting of hospital expenditure [2001,8, 1998,2].For providing end-to-end response or outsourcing business real-time decision support systems are required. But real-time decision support systems are complex because they must combine elements of several different types of technologies: enterprise integration, real-time systems, workflow systems, knowledge management, and data warehousing and data mining [2001,9 ]. Therefore to deal with the problem of integration of different types of technologies, intelligent DSS using collaboration technologies was implemented by putting the decision maker effectively in the loop of such DSS and to provide intelligent decision support, the expert knowledge is embedded within the DSS [2006,12]. We all know that emergency department is very crucial unit in every hospital as there is always a problem of overcrowding because of increasing population. But due to the evolution of computerized systems there is a relax ad people are working more effectively. EDIS has thus reduced the situation of overcrowding and thus decrease the waiting time. A Collaborative intelligence for intelligent diagnosis systems was developed using data mining technique to help the doctors to work efficiently. As the diagnosis rules are discovered, the knowledge base will become richer with the rules and thus diagnosis will become efficient [2010, 25].

Collaborative systems may be complex, distributed, open, and dynamic applications; on the other hand, the human factor plays a very important role with respect to other application fields. Collaboration between different organizations can be achieved by the openness of the systems, a feature that could lead to global collaboration [2006, 13]. Although collaboration increases complexity but it has many advantages too like Collaboration in health care leads to a greater utilization of existing infrastructure including doctors and equipment. To deliver lower costs services to the patients by avoiding costly duplicate tests, current service providers must share patient's fragmented medical record to obtain a collaborative advantage. Collaboration enables decentralized planning of primary health care in a region, sharing of resources, manpower and equipments of identification of hubs for proper control of health care services.

\section{A CONCEPTUAL FRAMEWORK \\ 3.1 HUB and SPOKE Model}

Hub and Spoke Model is a Decision Support System model that can be used in Load Balancing, Manpower Planning and Equipment Planning etc. To show collaboration between various health care centers, data from 4 districts of Delhi has been taken. First we consider the data from East of Delhi. The dispensaries in East of Delhi are DGD Bank Enclave enclave,
DGD Karkardoomadooma, DGD Surajmal Vihar Vihar, DGD Geeta Colony Colony and DGD Chander Nagar .

For Hub \& Spoke model, the inputs are name of dispensary, no. of doctors, present load per day and capacity of dispensary. By subtracting the capacity that a dispensary can absorb from patient load, we get the excess load.

Table 1: Hub \& Spoke model input for East district of Delhi

\begin{tabular}{|c|c|c|c|c|}
\hline $\begin{array}{c}\text { Name Of } \\
\text { dispensary }\end{array}$ & $\begin{array}{c}\text { No. } \\
\text { Of } \\
\text { doctor } \\
\text { s }\end{array}$ & $\begin{array}{c}\text { Prese } \\
\text { nt } \\
\text { load / } \\
\text { day }\end{array}$ & $\begin{array}{c}\text { Capacity } \\
\text { of } \\
\text { dispensa } \\
\text { ry }\end{array}$ & $\begin{array}{c}\text { Excess } \\
\text { load=prese } \\
\text { nt load- } \\
\text { capacity }\end{array}$ \\
\hline $\begin{array}{l}\text { Bank } \\
\text { Enclave }\end{array}$ & 3 & 179 & 108 & 71 \\
\hline $\begin{array}{l}\text { Karkardoo } \\
\text { ma }\end{array}$ & 4 & 180 & 144 & 36 \\
\hline $\begin{array}{l}\text { Surajmal } \\
\text { Vihar }\end{array}$ & 3 & 187 & 108 & 79 \\
\hline $\begin{array}{l}\text { Geeta } \\
\text { Colony }\end{array}$ & 3 & 224 & 108 & 116 \\
\hline $\begin{array}{l}\text { Chander } \\
\text { Nagar }\end{array}$ & 2 & 199 & 72 & 127 \\
\hline \multicolumn{4}{|c|}{ Total Excess load } & 429 \\
\hline
\end{tabular}

The Hub is selected to absorb all excess load (total excess load=429) transferred from the spokes while by design the spokes are constrained to their capacity. The Hub is selected according to load (volume). So the centre with the highest load i.e. dispensary "Geeta Colony" is the hub. This results in a hub and spoke model.

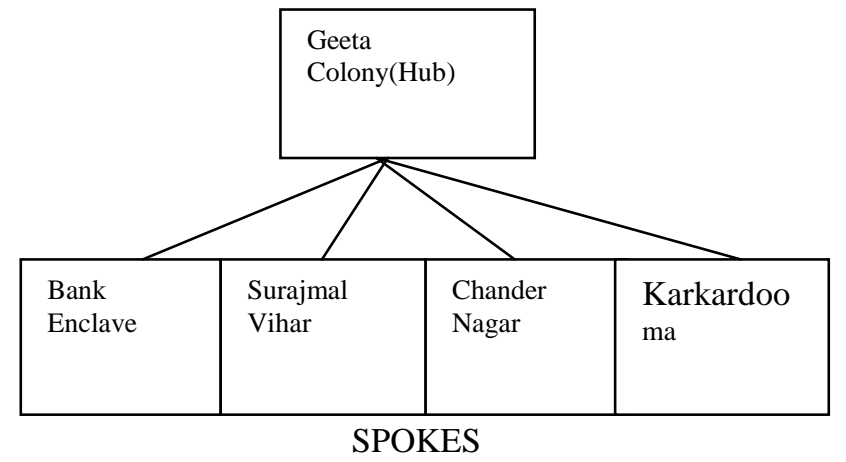

Fig 1: HUB \& SPOKE Network

From the table 2 it is clear that, the number of Doctors needed in Hub (Geeta Colony) is therefore 14.The hubs can also be chosen according to the distances between the dispensaries. Once a hub and spoke model is created, further requests for patient servicing can be satisfied by: The present hub or its spokes if they have free capacity. However if the present network is full, the requests for patient servicing must be redirected to the nearest hub and spoke network. Again search is performed in that network to determine if the request can be satisfied by the hub or by its spokes. 
Table2: New load distribution

\begin{tabular}{|c|c|c|}
\hline Name of centre & $\begin{array}{l}\text { New loads on } \\
\text { centre }\end{array}$ & No. Of Doctors \\
\hline Bank Enclave & 108 & 3 \\
\hline karkardooma & 144 & 4 \\
\hline Surajmal Vihar & 108 & 3 \\
\hline Geeta Colony & $108+429=537$ & 14 \\
\hline Chander Nagar & 72 & 2 \\
\hline
\end{tabular}

\subsection{Collaborative DSS Model}

The shortage of medicines, infrastructure and specialists is responsible for the failure of health care delivery system at the primary health care level (planning commission, 2001). So, there is a need of web enabled collaborative DSS to plan the deployment of doctors and medical equipment. Collaboration between two networks is of great advantage in terms of effective cost utilization, decentralization, load balancing and load sharing etc.. Collaboration is transfer of patient load between 2 networks. This is guided by metadata about the network. The utilization of multiple information sources to solve a problem creates a need for homogeneous access over heterogeneous information sources. Metadata is essential for understanding the structure of information, its quality and its relevance. The process of standardisation of metadata is models, semantics and syntax [23].Two tasks that must be done before the computation so that collaboration for a particular network starts with another network are:

(1).Preparing the Metadata Table: The information contained in the metadata table for a network corresponds to the entire networks in the problem space. This data is then entered into $\mathrm{m}$-data table for the network. This cycle is repeated for all the networks in the problem space. Master metadata table which contains the set of all such m-data tables is accessed by the controller.

\begin{tabular}{|l|l|l|l|}
\hline $\begin{array}{l}\text { Name of } \\
\text { HUB }\end{array}$ & $\begin{array}{l}\text { Name of } \\
\text { Spokes }\end{array}$ & $\begin{array}{l}\text { Free } \\
\text { capacity at } \\
\text { HUB }\end{array}$ & $\begin{array}{l}\text { Free } \\
\text { capacity at } \\
\text { spokes }\end{array}$ \\
\hline
\end{tabular}

Fig 2: Metadata table for the network

(2).Preparing the distance matrix: The distance matrix indicates the distance of one health care centre from other health care centers. The nearest distance hub from a requesting HUB centre is its collaborating network. The algorithm used in development of collaborative DSS model has been detailed in the earlier paper [30]

\subsection{Computation of Collaborative Network}

For implementation purpose the data from four primary health care centers situated in east, west, south, south west of Delhi are taken and each network consists of five centres. Following are the steps for the collaboration of networks:

1. HUB and SPOKE model is used to find the HUB and SPOKES.
2. Formulation of Metadata table that consists of Name of HUB, Name of Spokes, Free capacity at HUB and Free capacity at Spokes.

3. Collaboration between the networks is done to share the load and enhance decentralization. The implementation of collaborative DSS approach is done in Prolog. Static data and dynamic data is involved while implementing the concept of collaboration.

Static data is the data that do not change with time.

We have collected the data from Delhi health care centers. Patient load and dispensaries are taken as static data. Patient load has 2 arguments i.e. centre name and patient load. Dispensaries again has 2 arguments i.e. centre name and no. of doctors; whichever center has maximum patient load is selected as HUB i.e. Hub is selected by max patient load on a centre.

If pload $(a, 11)$, pload $(b, 12)$, .pload(n,ln) then $\max$ $(11,12 \ldots \ldots \ldots . \ln )=\mathrm{M}$

pload $(H, M)=H$ is obtained as the hub with maximum patient load.Structure of M-data for $1^{\text {st }}$ network

\begin{tabular}{|c|c|c|c|}
\hline $\begin{array}{l}\text { Name of } \\
\text { Hub } \\
\text { "Geeta } \\
\text { Colony" }\end{array}$ & $\begin{array}{l}\text { Name of } \\
\text { spokes } \\
\text { "karkardooma, } \\
\text { Surajmal } \\
\text { Vihar, Bank } \\
\text { Enclave, } \\
\text { Chander } \\
\text { Nagar" }\end{array}$ & $\begin{array}{l}\text { Free } \\
\text { capacity at } \\
\text { Hub-“not } \\
\text { free”, } \\
\text { overloaded- } \\
33\end{array}$ & $\begin{array}{l}\text { Free } \\
\text { capacity at } \\
\text { spokes- } \\
\text { "spokes are } \\
\text { full". }\end{array}$ \\
\hline
\end{tabular}

Fig 3: The M-data table for 1st network (East Delhi)

Excess load of a center as stated before is calculated by subtracting the capacity of the dispensary from patient load. A center is called overloaded center if excess load is positive and if excess load is negative, then it is called under loaded centre.

Thus total free capacity $\left(\mathrm{T}_{\mathrm{FREECAP}}\right)$ in the network is sum of free capacity in hub (HUB FREECAP) and free capacity in spokes (SPOKES FREECAP). Thus $\mathrm{T}_{\text {FREECAP=, HUB FREECAP+ }}$ SPOKES FREECAP . This information is stored in tables as shown in fig 2.

On the other hand capacity of a centre \& excess load of a centre are the dynamic data and will be asserted dynamically in the database. The prolog code for capturing the dynamic data is as follows:-

:-dynamic calculatecapacity / 0

calculatecapacity:- $\operatorname{disp}(\mathrm{X}, \mathrm{Y}), \operatorname{pload}(\mathrm{X}, \mathrm{Z})$,

$\operatorname{getcap}(X, Y, C), \operatorname{assert}(\operatorname{capacity}(X, Y, C))$,

$\mathrm{E}$ is $\mathrm{Z}-\mathrm{C}$.

assert ( excess $(\mathrm{X}, \mathrm{E}))$,

fail.

calculatecapacity:-!

New load distribution constraints (in the network):-

(a) $\mathrm{N}_{\mathrm{SPOKE}}<=\mathrm{C}_{\mathrm{SPOKE}}$ where $\mathrm{N}_{\mathrm{SPOKE}}$ is new load on a spoke and $\mathrm{C}_{\mathrm{SPOKE}}$ is the capacity of spoke. 
(b) $\mathrm{N}_{\mathrm{HUB}}=\mathrm{C}_{\mathrm{HUB}}+\mathrm{T}_{\text {EXCESS LOAD }}$ where $\mathrm{N}_{\mathrm{HUB}}$ is new load for a Hub, $\mathrm{C}_{\mathrm{HUB}}$ is capacity of Hub and $\mathrm{T}_{\text {EXCESS LOAD }}$ is total excess load in the network. After the computation, the structure of M-data for healthcare centers in east of Delhi is shown in fig 4.

\section{SIMULATION AND RESULTS}

Same method is applied for other healthcare centers in South Delhi, West Delhi and South West Delhi. And Meta-data tables are obtained for each of the regions that would be helpful while collaboration takes place between the healthcare centers.

\subsection{Computation of Meta Datatable for South Delhi}

This network consists of 5 centres viz. Ayanagar (Seed PUHC Aya Nagar), Sangaml (Seed PUHC Sangam Vihar L block), Sangamb(Seed PUHC Sangam Vihar B block), Jawaharpark (Seed PUHC Jawahar Park) and Khanpur (DGD Khanpur).

Table 3: Hub \& Spoke Model input for South district

\begin{tabular}{|l|l|l|l|l|}
\hline $\begin{array}{l}\text { Name Of } \\
\text { Dispensary }\end{array}$ & $\begin{array}{l}\text { No. of } \\
\text { Doctors }\end{array}$ & $\begin{array}{l}\text { Present } \\
\text { load/day }\end{array}$ & $\begin{array}{l}\text { Capacity } \\
\text { of } \\
\text { dispensary }\end{array}$ & $\begin{array}{l}\text { Excess } \\
\text { load }\end{array}$ \\
\hline Ayanagar & 2 & 252 & 72 & 180 \\
\hline Sangaml & 2 & 120 & 72 & 48 \\
\hline Sangamb & 1 & 100 & 36 & 64 \\
\hline Jawaharpark & 2 & 140 & 72 & 68 \\
\hline Khanpur & 2 & 250 & 72 & 178 \\
\hline Total excess Load in the network & 538 \\
\hline
\end{tabular}

After the calculation of excess load, we find the new load distribution for this network.

Table 4: New load distribution for South District network

\begin{tabular}{|c|r|r|}
\hline Name of centre & $\begin{array}{l}\text { New Loads on } \\
\text { centre }\end{array}$ & \multicolumn{2}{|l|}{ No of doctors } \\
\hline Ayanagar & $72+538=610$ & 16 \\
\hline Sangaml & 72 & 2 \\
\hline Sangamb & 36 & 1 \\
\hline Jawaharpark & 72 & 2 \\
\hline Khanpur & 72 & 2 \\
\hline
\end{tabular}

Structure of M-data for $2^{\text {nd }}$ network

\begin{tabular}{|l|l|l|l|}
\hline $\begin{array}{l}\text { Name of } \\
\text { Hub } \\
\text { "Ayanagar" }\end{array}$ & $\begin{array}{l}\text { Name of } \\
\text { spoke } \\
\text { "Sangaml, } \\
\text { Sangamb, } \\
\text { Jawaharpark, } \\
\text { Khanpur" }\end{array}$ & $\begin{array}{l}\text { Free capacity } \\
\text { at Hub-"not } \\
\text { free", } \\
\text { overloaded- }\end{array}$ & $\begin{array}{l}\text { Free } \\
\text { capacity } \\
\text { at }\end{array}$ \\
$\begin{array}{l}\text { spokes- } \\
\text { "spokes } \\
\text { are full". }\end{array}$ \\
\hline
\end{tabular}

Fig 4: The M-data table for $2^{\text {nd }}$ network

\subsection{Computation of Meta Datatable for South West}

$3^{\text {rd }}$ network consists of 5 centres viz. Chhawla (DGD Chhawla), Dindrapur (DGD Dindrapur), Dharampur (Seed PUHC Dharampur), Gopalnagar (Seed PUHC Gopal Nagar), Bamnoli(DGD Bamnoli).

Table 5. HUB \& SPOKE Model Input for South West

\begin{tabular}{|c|c|c|c|c|}
\hline $\begin{array}{c}\text { Name Of } \\
\text { dispensary }\end{array}$ & $\begin{array}{l}\text { No. Of } \\
\text { doctors }\end{array}$ & $\begin{array}{c}\text { Present } \\
\text { load / } \\
\text { day }\end{array}$ & $\begin{array}{c}\text { Capacity } \\
\text { of } \\
\text { dispensary }\end{array}$ & $\begin{array}{c}\text { Excess } \\
\text { load }\end{array}$ \\
\hline Chhawla & 2 & 150 & 72 & 78 \\
\hline Dindrapur & 2 & 181 & 72 & 109 \\
\hline Dharampur & 1 & 180 & 36 & 144 \\
\hline Gopalnagar & 1 & 100 & 36 & 64 \\
\hline Bamnoli & 2 & 110 & 72 & 38 \\
\hline \multicolumn{4}{|c|}{ Total excess load in the network } & 433 \\
\hline
\end{tabular}

Table 6. New load distribution for South West district

\begin{tabular}{|l|r|c|}
\hline Name of centre & $\begin{array}{l}\text { New loads on } \\
\text { centre }\end{array}$ & No. Of Doctors \\
\hline Chhawla & 72 & 2 \\
\hline Dindrapur & $32+433=505$ & 14 \\
\hline Dharampur & 36 & 1 \\
\hline Gopalnagar & 72 & 1 \\
\hline Bamnoli & 36 \\
\hline
\end{tabular}

Structure of M-data for $3^{\text {rd }}$ network

\begin{tabular}{|l|l|l|l|}
\hline $\begin{array}{l}\text { Name of } \\
\text { HUB- } \\
\text { "Dindrapur" }\end{array}$ & $\begin{array}{l}\text { Name of } \\
\text { Spokes- } \\
\text { "Chhawla, } \\
\text { Dharampur, } \\
\text { Gopalnagar, } \\
\text { Bamnoli" }\end{array}$ & $\begin{array}{l}\text { Free capacity } \\
\text { at HUB- } \\
\text { "not free" }\end{array}$ & $\begin{array}{l}\text { Overloaded= } \\
\text { capacity } \\
\text { at } \\
\text { spokes- } \\
\text { not free }\end{array}$ \\
\hline
\end{tabular}

Fig 5: The M-data table for 3rd network

\subsection{Computation of M-data table for West district}

$4^{\text {th }}$ network consists of 5 centres viz. Hirankudna (DGD Hiran Kudna), Nangloi(DGD Nangloi), Nihalvihar (Seed PUHC Nihal Vihar),Kapashera (DGD Kapashera), Chandernagar(Seed PUHC Chander Nagar Vihar). 
Table 7.HUB \& SPOKE Model Input for West district

\begin{tabular}{|l|r|r|r|r|}
\hline $\begin{array}{c}\text { Name Of } \\
\text { dispensary }\end{array}$ & $\begin{array}{r}\text { No. Of } \\
\text { doctors }\end{array}$ & $\begin{array}{c}\text { Present } \\
\text { load / } \\
\text { day }\end{array}$ & $\begin{array}{c}\text { Capacity } \\
\text { of } \\
\text { dispensary }\end{array}$ & $\begin{array}{c}\text { Excess } \\
\text { load }\end{array}$ \\
\hline Hirankudna & 1 & 85 & 36 & 49 \\
\hline Nangloi & 2 & 185 & 72 & 113 \\
\hline Nihalvihar & 2 & 119 & 72 & 47 \\
\hline Kapashera & 3 & 234 & 108 & 126 \\
\hline Chandernagar & 2 & 160 & 72 & 88 \\
\hline \multicolumn{5}{|c|}{ Total excess load in the network } \\
\hline
\end{tabular}

Table 8. New load distribution for West district

\begin{tabular}{|l|r|c|}
\hline Name of centre & $\begin{array}{l}\text { New loads on } \\
\text { centre }\end{array}$ & No. Of Doctors \\
\hline Hirankudna & 36 & 1 \\
\hline Nagloi & 72 & 2 \\
\hline Nihalvihar & 72 & 2 \\
\hline Kapashera & $108+423=531$ & 14 \\
\hline Chandernagar & 72 & 2 \\
\hline
\end{tabular}

Structure of M-data for $4^{\text {th }}$ network

\begin{tabular}{|c|c|c|c|}
\hline $\begin{array}{l}\text { Nam } \\
\text { e of } \\
\text { HUB } \\
- \\
\text { "kap } \\
\text { a" }\end{array}$ & $\begin{array}{l}\text { Name of Spokes- } \\
\text { "hiran, nihal, } \\
\text { nangloi,Chander } \\
\text { Nagar" }\end{array}$ & $\begin{array}{l}\text { Free capacity } \\
\text { at HUB-"not } \\
\text { free" } \\
\text { Overloaded=2 } \\
7\end{array}$ & $\begin{array}{l}\text { Free } \\
\text { capacit } \\
\text { y at } \\
\text { spokes } \\
- \text { not } \\
\text { free }\end{array}$ \\
\hline
\end{tabular}

Fig 6: The M-data table for 4th network

Now the networks are named by their respective hubs, they are: Geeta Colony (for DGD Geeta Colony Colony), Ayanagar (for Seed PUHC Aya Nagar), Dindrapur (for DGD dindrapur) and Kapashera (for DGD kapashera). Accordingly, the distance matrix can be formulated giving the distance of hubs from each other as shown below. Figure below shows how communication occurs between the collaborative networks. Here M1, M2, M3, M4 represents metadata information (fig 4, 5, 6,7) with the help of which a network will find a meta data for another network. Also a network determines its adjacent network using the distance matrix described below.

Table 9: Distance Matrix Showing Hub Connectivity

\begin{tabular}{|l|l|l|l|l|}
\hline & $\begin{array}{l}\text { Geeta } \\
\text { Colony }\end{array}$ & Ayanagar & Dindrapur & Kapashera \\
\hline $\begin{array}{l}\text { Geeta } \\
\text { Colony }\end{array}$ & 0 & 33 & 42 & 32 \\
\hline
\end{tabular}

\begin{tabular}{|l|l|l|l|l|}
\hline Ayanagar & 33 & 0 & 26 & 11 \\
\hline Dindrapur & 42 & 26 & 0 & 16 \\
\hline Kapashera & 32 & 11 & 16 & 0 \\
\hline
\end{tabular}

The distance from a dispensary to itself is marked as ' 0 '. From the table it is clear that for Hub "Geeta Colony", hub "Kapashera" is the nearest hub. Accordingly, metadata for the network named by Hub "Kapashera" is displayed and free load can be estimated, facilitating collaboration through load transfer, between these two networks.

Table 10: Distance Matrix from One Hub to Other Hubs

\begin{tabular}{|l|l|l|}
\hline From & To & Distance \\
\hline Geeta Colony & Ayanagar & 33 \\
\hline Geeta Colony & Dindrapur & 42 \\
\hline Geeta Colony & Kapashera & 32 \\
\hline
\end{tabular}

Since there is no free capacity at Hubs and Spokes of $2^{\text {nd }}$ network so the controller will consult the M-data table of the $3^{\text {rd }}$ network. Again there is no free capacity to collaborate. Therefore the controller will consult the $4^{\text {th }}$ network. Since there is no free capacity, therefore collaboration is not possible and hence load transfer is not possible.

\section{RESULTS AND DISCUSSIONS}

We have taken 4 networks and 5 health care centres in each network. According to the distance matrix shown above the HUB "Geeta Colony" choose the HUB "Kapashera" because it has minimum distance to as compared to hub "Ayanagar" and hub "Dindrapur". Since "hub Kapashera" has no free capacity, therefore next network is searched for the load transfer.

A request for collaboration is directed to Metadata Table by a controller, which controls the collaborative process. By searching the metadata table, the collaborative network is obtained for the requested network. After that free capacity computation is done for the networks which facilitate collaboration through load transfer. The metadata tables can be suitably updated after load transfer has taken place. Hub"Geeta Colony" determines that there is no network that has free capacity and to which load can be distributed.

The significance of this architecture lies in the fact that it is the hub in a network that determines the rules for collaboration. The spokes cannot take this decision at their level.

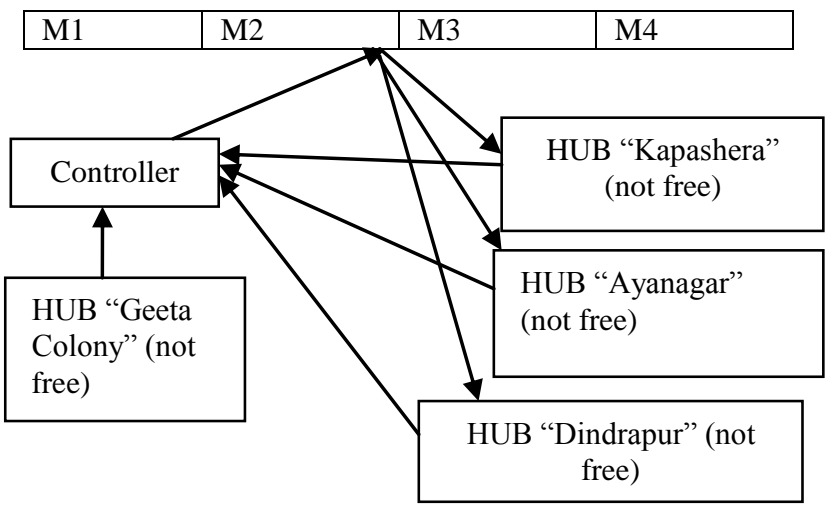

Fig 7: Collaboration of "Geeta Colony" with "other hubs" 


\section{CONCLUSIONS}

The existing HUB \& SPOKE Model is used as the basis for collaboration and the concept of metadata and controller is illustrated. If no free capacity exists in minimum distance hub network, then the next minimum distance network is selected as a candidate network for the collaboration. Further enhancements can be done in this model by maintaining a queue of request in real time which would help in addressing the live queries. The concept of priority can be used to designate some networks as priority networks which will satisfy only priority requests and this concept can be implemented by priority scheduling algorithm using a priority field in Meta data for the network. Thus the Meta-data template is extensible.

The code for the implementation of this model can be written in any programming language. In this paper, code for Hub selection was written in prolog, which can be extended to cover selection of spokes and the creation \& manipulation of metadata. This results in the design of a knowledge based system that involves dynamic database updates. The chosen hubs can also be used for providing telemedicine facility and financial planning for the network they represent.

\section{RECOMMENDATIONS}

The most important objective of this research paper is to establish an online DSS at the district level. The online DSS ensures that health care planners take effective decisions in real time that will lead to effective utilization of resources and thus helpful in load balancing. Therefore DSS enables:

1. Load balancing, through transfer of patient load.

2. Decentralization of health care services.

3. Hubs can be developed as telemedicine centers of consultation, to save deployment of specialists at spokes.

4. Financial allocation of resources can be done better in the new hierarchy.

5. Collaboration between different networks in the given problem spaces.

6. Strengthening of primary healthcare services in a region by minimizing referral to secondary care.

7. Monitor utilization of existing resources in a health set up by data analysis and decision support.

8. Set up a medical record department in each primary health center, so that data storage and access is easy and better.

9. Use call centers and information kiosks for better service delivery.

The other recommendation is to create the required ICT infrastructure in every district.

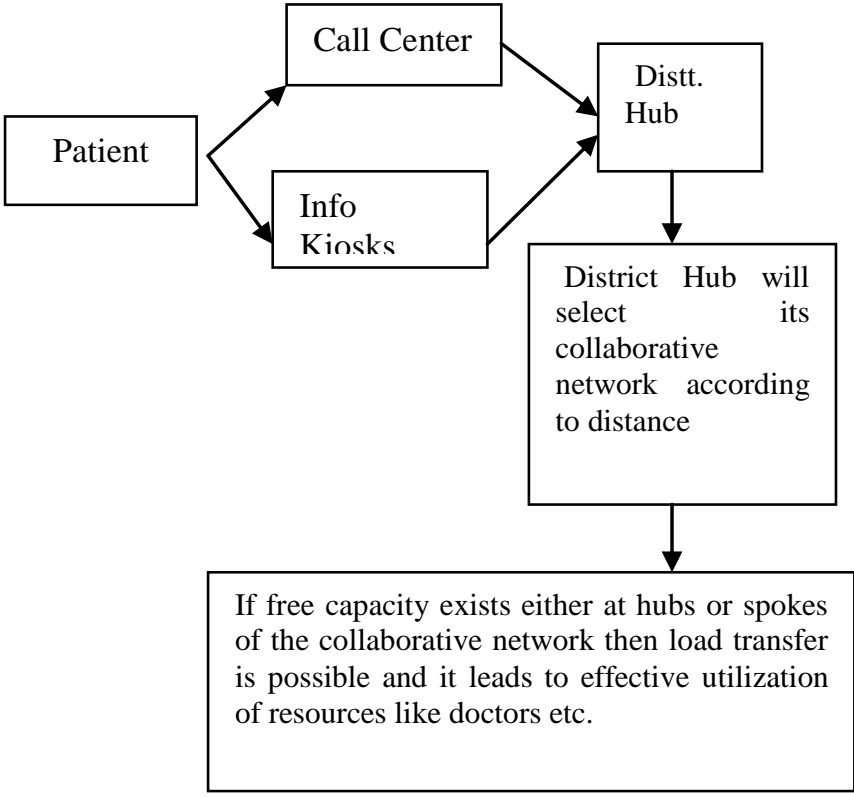

Fig 7: ICT architecture at district level

\section{REFERENCES}

[1] Shortliffe 1986. Medical Expert Systems -Knowledge Tools for Physicians. Western Journal of medicine, vol. 145(6), 830-839.

[2] Scally G \& Liam J Donaldson 1998. Clinical governance and the drive for quality improvement. British Medical Journal, vol. 317, 61-65.

[3] P. Zarate, C. Rosenthal-Sabroux 1998 .A Cooperative Approach for Intelligent Decision Support Systems. In proceeding of the $31 s t$ Annual Hawaii International Conference on System Sciences.

[4] G.R.Rao 2000. A hypermedia-based group decision support system to support collaborative medical decision-making. Decision Support Systems, vol 30, 187216.

[5] Efraim Turban Jay E. Aronson 2001. Decision Support Systems and Intelligent Systems: Pearson Publications.

[6] Daniel J. Power 2001. Supporting Decision-Makers: An Expanded Framework. Informing Science -Challenges to Informing Clients: A Transdisciplinary Approach, 431436.

[7] A.M. Thornett 2001. Computer Decision support systems in general practice. International journal of Information Management, vol 21, 39-47.

[8] Khan Akbar Ali M 2001. Cost and efficiency of public hospitals: A cross sectional analysis. South Asian journal of Management, vol 10, 33-53.

[9] Kemal A. Delic, Laurent Douillet, Umeshwar Dayal 2001. Towards an Architecture for Real-Time Decision Support Systems: Challenges and Solutions. International Symposium on Database Engineering and Applications, 303-311.

[10] Ranjit Bose 2004. Knowledge management-enabled health care management systems: capabilities, infrastructure, and decision-support. Expert Systems with Applications, vol 24, 59-71. 
[11] Aggarwal Satish 2006. E- Governance for administrative effectiveness, Prashasnika, volume xxxii no 1, 41-53.

[12] Abdelkader ADLA, Pascale Zarate 2006. A Cooperative Intelligent Decision Support System. IEEE Xplore, 1-6.

[13] Guest Editorial 2006. Special Issue on Collaboration Support Systems. IEEE Transaction on systems, man, and cybernetics-PART A: Systems and humans, vol. $36,1042-1044$

[14] D.J. Power 2007. A Brief History of Decision Support Systems. http://DSSResources.COM/history/dsshistory.html, version 4.0 .

[15] Jian Yang, Zhong Zhang, Hong Feng 2008. Mathematical Modeling for the Health Care System. International Conference on Intelligent Computation Technology and Automation, 608-612.

[16] Peter A. Bath 2008. Health informatics: current issues and challenges. Journal of Information Science, vol. 34, 501-518.

[17] Xiangmin Zhang, Yuelin Li 2008. Use of collaborative recommendations for web search: an exploratory user study. Journal of Information Science, vol. 34 , 145-161.

[18] Jianjun Lv, Zhishu Li 2009. Research on Architecture of Decision Support System. 2nd IEEE international conference on Computer Science and Information Technology,199-202.

[19] Olga Sustersic, Uros Rajkovic, Vesna Prijatelj, Vladislav RajkovIC 2009. Evaluating Patient's Health by a Hierarchical Decision Model. International Conference on eHealth, Telemedicine, and Social Medicine, 136139.

[20] www. healthmanagement.com.

[21] Tawhik et. al 2009. Understanding Clinical Work Practices for Cross-Boundary Decision Support in eHealth. Information Technology in Biomedicine. IEEE Transaction on, vol 16(4), 530-541.
[22] Terry Young 2009. Three Critical Challenges for Modelling and Simulation in Healthcare. Winter Simulation Conference, 1823-1830.

[23] Keith G Jeffery. METADATA: The Future of Information http://www.wmo.int/pages/prog/www/WDM/ETIDM/Doc-2-3.htm

[24] The information centre for health and social care (n.d.) http://www.ic.nhs.uk/casemix

[25] Jianjun Lv, Zhishu Li 2009. Research on Architecture of Decision Support System. In Proc. of 2nd IEEE international conference on Computer Science and Information Technology, 199-202.

[26] Sung Ho Ha, Zhenyu Zhang 2010. Collaborative intelligence for intelligent diagnosis systems in hospital environment. International conference on knowledge discovery and data mining, 532-535 .

[27] Tiago et.al 2013. Health Functional Units Sentinel Network, A Learning Device and Decision Support System in Health Functional Units at Portuguese primary Health Care Level. International Conference on Health and Social Care Information Systems and Technologies, vol 9, 1329-1334

[28] Chun hua et. al 2013. An Integrated Model for Patient Care and Clinical Trials to support clinical research visit scheduling workflow for future learning health systems. Journal of Biomedical Informatics, vol 46, 642-652.

[29] Mor Peleg 2013. Computer-interpretable clinical guidelines: A methodological review. Journal of Biomedical Informatics, vol 46, 744-763.

[30] Pahuja Gunjan \& Vohra Rajan 2012. Collaborative Decision Support Systems for Primary Health care Managers. International Journal of Computer Science Issues, vol 9(2), 416-421. 